\title{
Development of Creativity in Concurrent Engineering Teams
}

\author{
Alireza Aslani*, Petri Helo, Marja Naaranoja \\ Industrial Management Department, University of Vaasa, Vaasa, Finland. \\ Email: *alireza.aslani@uwasa.fi \\ Received December $13^{\text {th }}, 2011$; revised April 5 ${ }^{\text {th }}, 2012$; accepted April 26 ${ }^{\text {th }}, 2012$
}

\begin{abstract}
The development of successful new products is today of challenge to most consumer product companies. They have to short their response time, pushing their development processes to move faster while keeping on competitive prices and quality. These caused companies are forced to find effective and innovative approaches as work methods to overcome to pressures. Concurrent Engineering (CE) is one of the approaches to address these managerial and manufacturing dilemmas in new product projects. The basic premise of CE revolves around team working. However, most of the managers especially project managers face with problems when they want to promote teamwork culture, especially in conditions that the project faces with complicated problems. In this condition, a creative team consists of members from different levels of the organizational hierarchy must be shaped. There are always barriers in group meetings that influence growth and diffusion of creative solutions and would be reduced by using creativity and innovation techniques. The first purpose of this study is to identify the effective criteria in success of creative meetings in CE projects. Next, the prioritization of each factor has been analyzed and ranked respectively. Finally, based on the results of previous research of the authors, the useful group creativity and innovation techniques related with team work meetings in CE projects have been ranked by using the Analytic Hierarchy Process (AHP) approach.
\end{abstract}

Keywords: Concurrent Engineering; Decision Making; Uncertainty; Teamwork; Creativity Techniques; AHP

\section{Introduction}

Over the past decade companies in almost all markets have been facing a level of competitiveness. They have found that a successful product should be offered to markets in two different strategies, with high quality and competitive price, or earlier than other competitors. In the second strategy firms require to produce more new products and reduce the time for marketing [1]. This causes firms and researchers force to find effective and innovative approaches in product development (PD) [2]). Concurrent Engineering (CE) is one of the integrated product development (PD) approaches with emphasis on response to markets expectations by producing better, effective cost and faster products [3].

Doing works simultaneously, focusing on the process, and converting hierarchical organizations into teams are the key principles of CE [4]. In CE, teams of specialists from different disciplines are encouraged formally to work together. A typical team would consists of industrial, mechanical, electrical, software and quality engineers, failure analysis, and sales and marketing employees and customer representative.

${ }^{*}$ Corresponding author.
Despite the widely verifiable benefits of using CE, according to researches, the numbers of $\mathrm{CE}$ projects which can't reach fully to predetermined goals are noticeable [5]. From different viewpoints these failures can be justified such as; project management, engineering, budgeting, team efficiency and etc. [6].

One of the inherent weaknesses of CE is related with team's problems and limitations. Several issues are affected on the efficiency of CE teams in PD (circumstance of choosing team members, forming or disbanding of teams, dominating teamwork culture among the members by supporting leader's and etc.) [6]. The deficiency of effective CE team shows itself particularly when a PD project faces with complicated or uncertainty in which team members are needed to evaluate and solve the problems. This uncertainty would be a technical problem in PD process or a new governmental law and etc. According to experiences of the authors, in such conditions, managers need to have more information to analyze and understand different dimensions and effects of the problem on their projects. Further, they would need to creative solutions to overcome to the problem [7]. Since in the team meetings consists of different levels of manag- 
ers, experts, and related staffs mostly atmosphere of the team is affected by organizational hierarchy, usually the resultants of the decisions aren't consistent with expectations [8].

The first purpose of this research is to identify the effective criteria in success of creative meetings particularly when CE teams are created to find new and creative solutions for complicated and uncertain problems of projects. Next, the prioritization of each factor would be analyzed and ranked respectively. Finally, according to the previous researches of the authors, the useful group creativity and innovation techniques related with strategic team work meetings would be ranked by using the Analytic Hierarchy Process (AHP) approach. In this regard, three main questions have been answered in this article:

- What is the role of creativity and innovation in CE team's decision making when the PD project faces with a complicated or uncertain problem?

- What are the effective criteria in success of meetings in this condition?

- To diffuse the creativity among CE team members, which identified creativity techniques are in priority for implementation?

\section{Literature Review and Theoretical Framework}

Different definitions have been used for concurrent engineering (CE). For instance, Pennell defines $\mathrm{CE}$ as a systematic approach to integrated design of products and related processes [9]. This approach is considered in three different frames; people, process and Technology (Figure 1) [10]. Recent evidences show that $\mathrm{CE}$ can cause $30 \%$ to $70 \%$ less development time, $65 \%$ to $90 \%$ fewer engineering changes, $20 \%$ to $90 \%$ less time to market, $200 \%$ to $600 \%$ higher quality, and $20 \%$ to $110 \%$ higher white collar productivity [11].

One of the basic CE characteristics is to utilize teams which focus on the project. Each team consists of different disciplines and various level of organization. Five major teams have been defined in CE namely; project management team, new technology team, cross-functional product development team, cross-functional process development team, and product team. Each team involves

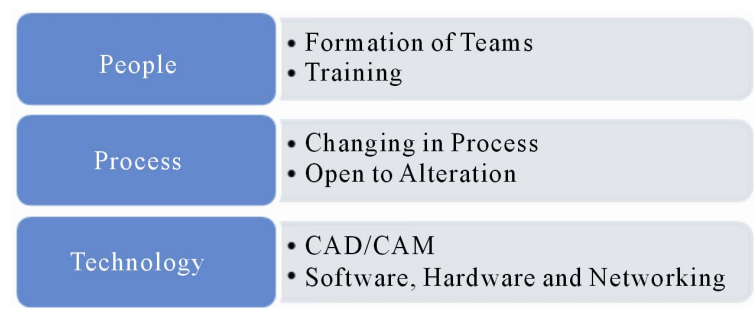

Figure 1. Main frame of CE [4]. people from different functional areas with different size which depend on the project. Although the scope of each team is different but one of the main purposes of them is to help to project managers to make a good decisions in critical and complicated conditions when the project engage to uncertainty in the environment and etc. [12]. For instance, there are several such examples in CE projects of software engineering which creative ideas or solutions are encouraged [13].

Basically, there are some gaps and challenges in team working that is noticeable in CE project teams too. Since in CE projects members from different disciplines with specific goals are engaged, and they might have never worked on teams, managers face with several challenges to keep the performance of the team in desirable expectation level. In this condition, some suggestions are encouraged to improve the team performance such as; sharing of knowledge, engaging in social interactions, and training in CE teams [14]. For instance, Skalak mentions training as a critical point for team works that can solve incompatibility issues among team members [12]. Boyle suggests some types of CE practices; specifically IT tools (e.g. rapid prototyping, simulation, integrated IT tools) for improving team effectiveness [15]. Grewin and Barrowman also indicate the influences of communication quality in succeeding team works in CE [16].

On the other hand, today CE project managers need team members who have high level of technical skills with ability to think creatively and innovative [17]. Due to the positive correlation between creativity and ability for problem solving, application of creativity and innovation in CE project meetings would be a solution for team working in uncertainty conditions [18]. In this approach, the solutions of a creative team would be more effective. Since the mental activity of a human declines and even stops after finding first or second solutions for a problem, the importance of using creative members and teams in decision making can be interpreted from environmental restrictions of the decisions too [8]. So, creative persons can extend the decision space of the team and groups and thereby managers of the $\mathrm{CE}$ projects can analyze the problems from different viewpoints. Therefore not only the quality of the decisions would be improved by right cognition of conditions and problems, but also can lead to create better and quicker solutions [19].

However, creative suggestions are a missing ring in teams that usually managers are displeasure about them [7]. According to researches, in teamwork meetings consist of different organizational hierarchy such as experts, top managers and etc., we should not expect for rising creative and new ideas and suggestions [20]. A collection of individual, collective and organizational barriers exists that always effect on organizational meetings. In normal teams of an organization, series of limitations may hinder 
the managers hopes for flourishing creativity of staffs [18]. There is always the possibility of idea following among members in ordinary teams. Also the freedom opinion express of lower organizational staffs probably would be declined because of fearing to ridicule by managers or other team members [7]. Furthermore, they might be worried about low levels of cynicism and harsh judgments. Also the lower ranked managers may not have willingness to state their ideas before a higher ranked group [21].

Regarding these barriers, the researchers of creativity and innovation suggest some methods to improve creative solutions. For example, the individuals and organizations must learn to improve their intuitive abilities or they must emphasize on a creativity fostering culture [22]. For well-structured problems these suggestions would be solved if the right procedure or algorithm is known. In contrast and, the solutions will be more undirected, intuitive and random in bad structure and complicated problems. In this case there are some rules or methods which stimulate human thoughts and help people to get over the passive "waiting for an idea". Such rules which experiential increase the probability of finding solutions are called heuristics [7]. Creativity Techniques are the frameworks which include selected heuristics for directed stimulation of thinking processes [20]. According to the recent survey, about $80 \%$ Austrian companies have used creativity techniques at least once, and $69 \%$ of them said that these techniques are useful for generating great ideas or solving daily problems [23]. This shows that the creativity techniques can be as an important part of organizational processes especially in problem solving.

In this regard, the researchers of this study have proposed a framework for improving the role of creativity and innovation in strategic decision making in the organization [24]. The creativity and innovative techniques are like toolbox, while all of them are very useful but we have to pick the right tool for our job. So we have identified the most important group creativity and innovation techniques to foster the emergence of creative and innovative ideas in uncertainty situation for strategic decision making. These techniques are; Brainstorming, Delphi, Scenario building, Story Boarding, Synectics, lateral thinking, Mind Mapping and TKJ Technique. They have been identified from more than 160 different creativity techniques which are different insights of different terms (Table 1) [7].

\section{Summery Review of Success Criteria of Creative Teams in CE Project's Meetings}

Decision making in uncertainty conditions, especially for complicated problems, is completely different ordinary
Table 1. Creativity techniques useful in CE team meetings [7].

Identified Techniques
Brainstorming
Delphi
Scenario Building
Story Boarding
Synectics
Lateral Thinking
Mind Mapping
TKJ

one [25]. In the uncertainty conditions, the decision maker of CE project has no or few knowledge about how to adequately behave, react, decide or think to the problem, due to lack of information, the number of variables and the amount of links. Consequently, improvement of creative thinking between team members extends the space and quality of the decisions of CE meetings. There are differences between problem solving and creative thinking. Problem solving is more objective, directed toward some goal, and must be more constant with the facts, while creative thinking is more personal and less fixed. Creative thinking also likes to involve more intuition and imagination than the more objective problem solving. In this way, the important question is, "what factors are important in development of creative thinking among team members CE project?”

In order to extracting factors, four scopes have been identified from literature review; CE and project management, team-making and working, creativity and innovation in individual, groups, and organization levels, and finally, decision making in uncertainty and complicated situations (Figure 2).

Since one of the purposes of CE teams is to streamline the total time of PD, CE teams start to work parallelly. This leads to accelerate execution of linked processes [26]. Hence, time has an important role in CE teams [27]. As a creativity technique should help to speed decision making process, the technique that result the best solution in the shortest time is more significant. The researchers have called this factor as "Rapidity in conclusion" index.

CE teams would be more successful through closer interactions among other members [26]. Because of the importance of interactions and communications in teams, members with high social skill are more successful in CE team meetings [28]. As one of the aims of creativity techniques, the group creativity techniques that can improve the interactions among team members will be in priority 


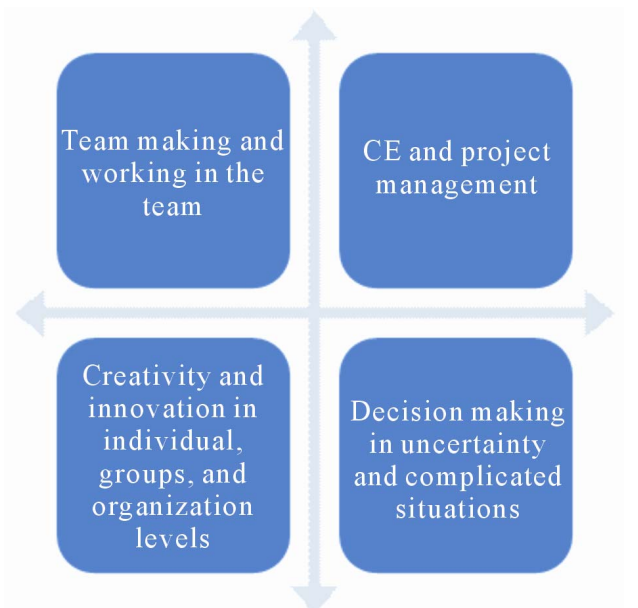

Figure 2. Fields of study for identifying criteria.

for using in CE teams. This trait has been called the index of "Social skills Improvement".

A successful CE project has a cohesive structural system in management, performance evaluation, training, and teams $[29,30]$. Cohesion in a team promotes communication among the team players [31]. A cohesive team has well-defined role and group norms, common goals, and a positive team identity. A creativity technique which encourages these characteristics is more noticeable in $\mathrm{CE}$ teams. A cohesive team causes to mutual respect among team members too.

Working concurrently in the opposite way of sequential approach, reduces PD time and budgeting and improves quality [3]. Due to the aim of creativity techniques in CE teams, the techniques should provide solutions which can improve the way of working to increase work performance. This feature ameliorates the performance of teams and the productivity of the project.

The problems in CE projects might have undetermined nature. As an example, environmental complexity is one of those issues which happen when managers face with different information [32]. In this situation, making good decision is not easy for managers. So they feel their project fall in an uncertainty condition. From strategic point of view, uncertainty is evaluated in two dimensions of complexity and rate of change [33]. According to previous researches, in this conditions decision makers need to think in time and consider to related internal and external factors of the problem to improve the quality of the decisions [7]. Therefore, the creativity technique that improves this way of thinking among team members is more important to select in CE meetings.

Since one of the important reasons for using creativity techniques in $\mathrm{CE}$ teams is to overcome to the barriers of creative thinking, the team members should express their opinion freely to provide the appearance's preface of creative solutions [34]. So a creativity technique should develop motivation and professional skills of team members and cause a liberty to make and utter ideas. Therefore the factors; "Self-development" and "Idea making freely" have been extracted to compare the ability of each technique from this point of view.

According to the literature review, seven main criteria have been extracted that ensure the successful of creative CE project teams meeting. These criteria can be classified in three main groups: task performance, team development, and professional development according to Slem definition [35]. Because a successful CE team must complete its task in an effective manner, the team members should function well together. Also working in the team should be a professional benefit for the team members. The structure of the factors and short description of them has been shown in the Figure $\mathbf{3}$ and Table 2.

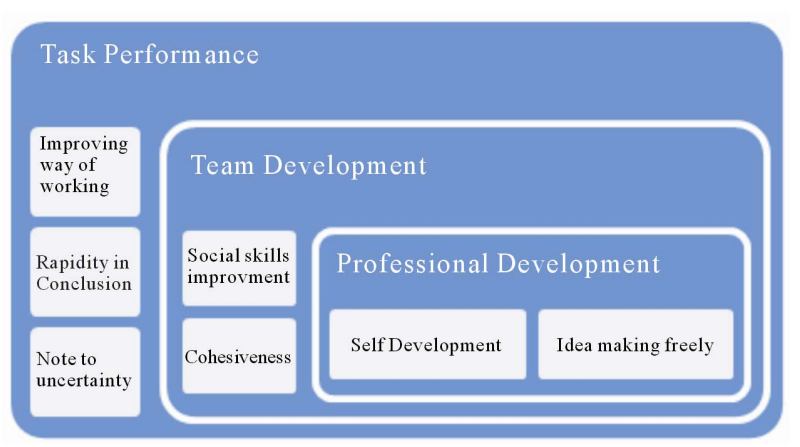

Figure 3. The structure of the identified criteria in succeeding of creative teams in CE projects.

Table 2. Description of the identified criteria.

\begin{tabular}{|c|c|c|}
\hline $\begin{array}{l}\text { Main } \\
\text { Characteristic }\end{array}$ & Criteria & Description \\
\hline \multirow{3}{*}{$\begin{array}{l}\text { Task } \\
\text { Performance }\end{array}$} & $\begin{array}{l}\text { Improving way of } \\
\text { working }\end{array}$ & $\begin{array}{l}\text { The technique can improve } \\
\text { ways to perform works in } \\
\text { team meeting }\end{array}$ \\
\hline & $\begin{array}{l}\text { Rapidity in } \\
\text { conclusion }\end{array}$ & $\begin{array}{l}\text { The technique will increase } \\
\text { speed of finding solutions }\end{array}$ \\
\hline & $\begin{array}{l}\text { Note to } \\
\text { uncertainty }\end{array}$ & $\begin{array}{l}\text { The technique encourage } \\
\text { members to think extra key } \\
\text { factors of problem like } \\
\text { environment and etc. }\end{array}$ \\
\hline \multirow{2}{*}{$\begin{array}{l}\text { Team } \\
\text { Development }\end{array}$} & $\begin{array}{l}\text { Social skills } \\
\text { improvement }\end{array}$ & $\begin{array}{l}\text { The technique encourage to } \\
\text { associate team members } \\
\text { together }\end{array}$ \\
\hline & Cohesiveness & $\begin{array}{l}\text { The techniques has cohe- } \\
\text { siveness for implementing } \\
\text { in teams of CE }\end{array}$ \\
\hline \multirow{2}{*}{$\begin{array}{l}\text { Professional } \\
\text { Development }\end{array}$} & Self-development & $\begin{array}{l}\text { The technique help team } \\
\text { members to develop } \\
\text { motivation and } \\
\text { professional skills }\end{array}$ \\
\hline & $\begin{array}{l}\text { Idea making } \\
\text { freely }\end{array}$ & $\begin{array}{l}\text { The technique cause a } \\
\text { member has liberty in } \\
\text { making ideas and } \\
\text { uttering them }\end{array}$ \\
\hline
\end{tabular}




\section{Research Methodology}

\subsection{Research Type and Strategy}

The research type of this work is sorted as a R\&D (research and development) and a descriptive research (Figure 4). The study also is an objective research insight of epistemology and since the researchers have controlled the right process of doing research, the research strategy is a "survey research" from ontology point of view (Figure 5) [36].

Both quantitative and qualitative researches have been used in this research. The criteria have been identified by reviewing accredited books and scientific articles related with CE, team working, and creativity and innovation (qualitative part). For weighting and ranking of the criteria and techniques, the Group Pairwise Comparisons and Analytic Hierarchy Process (AHP) have been used as one of the best and valid methods of multi-criteria decision making (MCDM) [37]. The hierarchy structure consists of three main levels; goal, criteria and alternatives. The goal of this research is; prioritization of selective creativity techniques to improve the creative level of decisions in CE teams meetings. So based on seven effective and identified criteria and eight alternatives, the decision matrix has been defined.

\subsection{Empirical Survey and Implementation of AHP}

A questionnaire consists of pairwise comparisons of

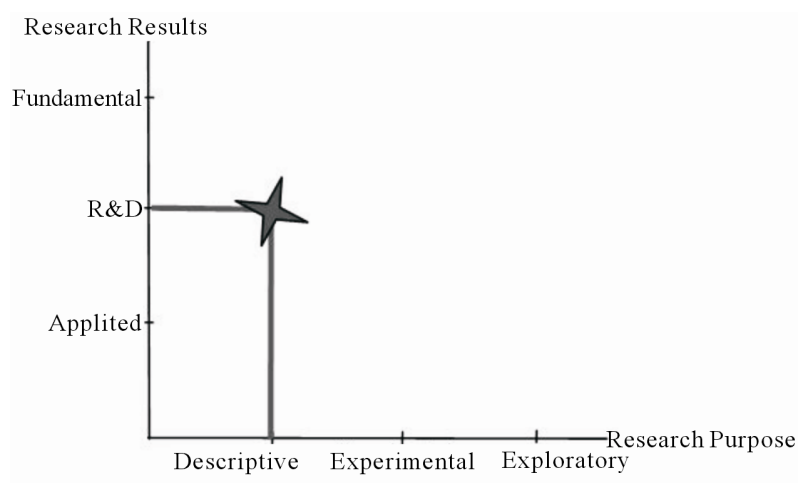

Figure 4. The research framework [36].

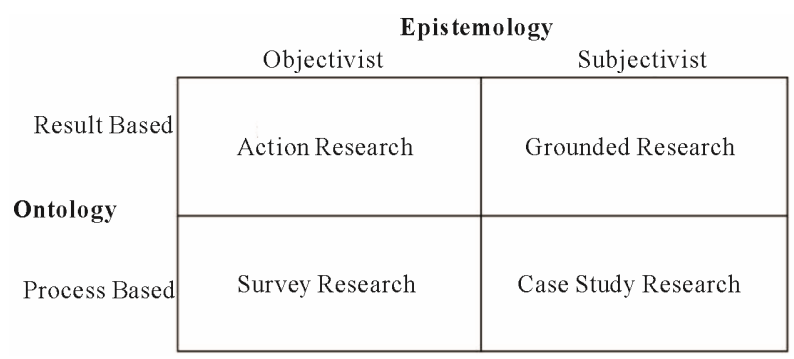

Figure 5. The research strategy [36]. seven criteria, and pairwise comparisons between eight alternatives (creativity techniques) with respect the criteria was design. The phrasing of the questions was formulated carefully in order to reflect the scales intensity of relative importance. The validity of the questionnaire was confirmed by using a standard table suggested by Saaty (Figure 6) [38].

\subsubsection{Data Collection}

The statistical population is managers, supervisors, and experts of product development and R\&D deputies who are working in complex projects in Iranian automobile manufacturing industry. Companies in this industry face with several market and governmental pressures to improve the quality of their products more quickly with lower costs to satisfy customers and regulations. These pressures have made challenges for three big companies who are producing in this industry. So they use CE approach in their PD projects. A survey with 45 responders has been selected from one of these big companies. They are working in R\&D and product development deputies and have adequately knowledge related with $\mathrm{CE}$ and creativity and innovation management. According to Howang, the data from these responses are completely sufficient for data analyzing by AHP method [39,40]. The age group of the respondents is between 25 and 40 with minimum bachelor degree.

\subsubsection{Data Analysis}

Expert Choice11 software has been used to analyze the questionnaires. The inconsistency of the responses was checked for each table by the software to ensure about the reliability of the research [38]. The weights of each index are the first results of software analysis (Table 3) (Figure 7).

\begin{tabular}{|c|c|c|}
\hline $\begin{array}{l}\text { Intensity of } \\
\text { importance }\end{array}$ & Definition & Explanation \\
\hline 1 & Equal importance & Two activities contribute equally to the objective \\
\hline 3 & Moderate importance & Experience and judgement slightly favour one over another \\
\hline 5 & Strong importance & $\begin{array}{l}\text { Experience and judgement strongly fav our one over } \\
\text { another }\end{array}$ \\
\hline 7 & Very st & $\begin{array}{l}\text { An activity is strongly favoured and its dominance is } \\
\text { demonstrated in practice }\end{array}$ \\
\hline 9 & Absolute importance & $\begin{array}{l}\text { The importance of one over another affirmed on the highest } \\
\text { possible order }\end{array}$ \\
\hline $2,4,6,8$ & Interme diate values & $\begin{array}{l}\text { Used to represent compromise between the priorities listed } \\
\text { above }\end{array}$ \\
\hline
\end{tabular}

Figure 6. Pairwise comparisons scales [38].

Table 3. Weights of criteria.

\begin{tabular}{cc}
\hline Factors & weight \\
\hline Improving way of working & 0.28 \\
Self-development & 0.2 \\
Cohesiveness & 0.153 \\
Note to uncertainty & 0.135 \\
Rapidity in conclusion & 0.102 \\
Social skills improvement & 0.082 \\
Idea making freely & 0.048 \\
\hline
\end{tabular}


As Figure 7 shows, the "Improving way of working" index has the most weigh among other criteria. This can be described from two different aspects; the importance of the performance in CE teams from expert's point of view, and the effects of creativity on quality of decisions. The general weights of three criteria that are in subset of Task Performance (Improving way of working, Rapidity in conclusions, and Note to uncertainty) have allocated $51.7 \%$ of weights. The Professional Development with 24.8\% and Team Development with 23.5\% have been weighted after Task Performance.

In the next step, the weights of alternatives in each criteria have been extracted. A part of the decision tree has been shown in Figure 8. For instance, insight of Social skills improvement index, the best three techniques are "Scenario Building”, "Synectics” and "Mind Mapping”.

Figure 9 illustrates the superiority of each technique in each criteria. This figure helps to decision makers to select the best creativity technique based on just one specific index.

Finally, the final ranking of creativity techniques has been specified by combination of weights in each technique (Table 4). According to Table 4, the best selected

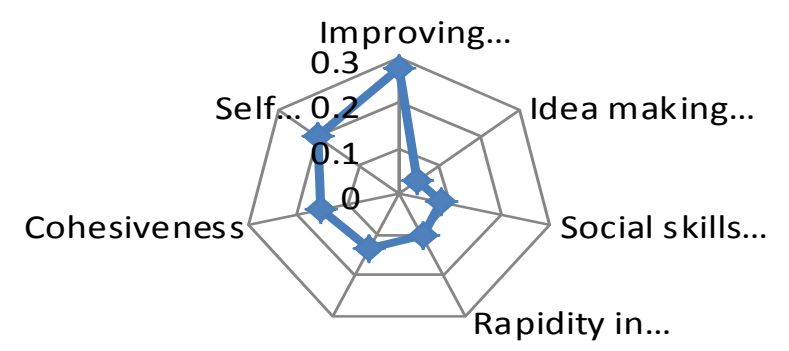

Figure 7. Situation of each criteria in compare with another.

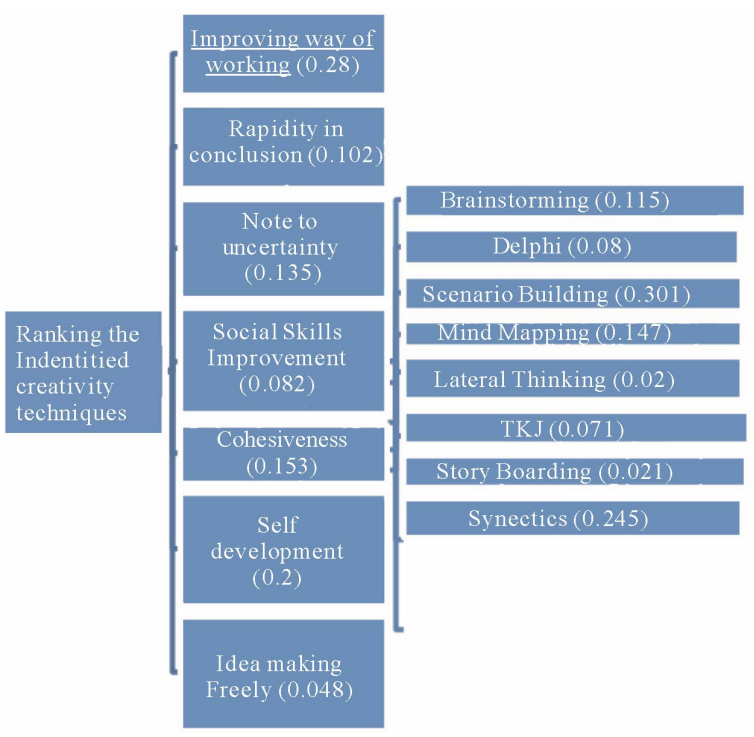

Figure 8. A sample of decision tree.

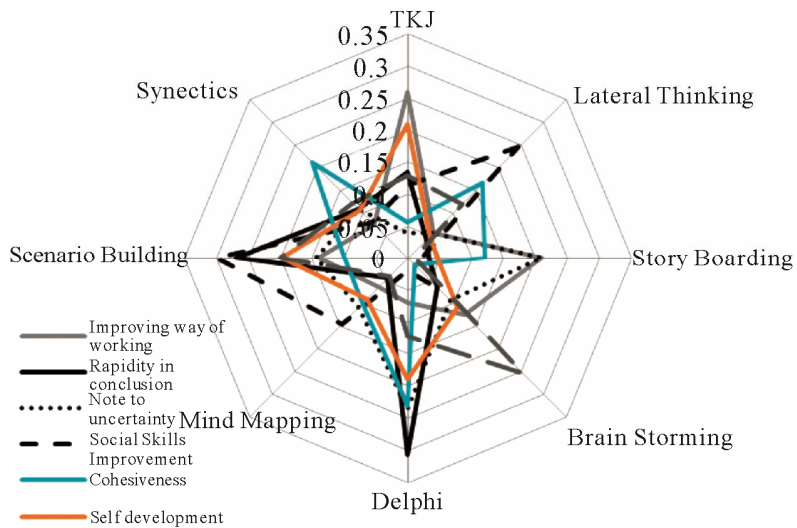

Figure 9. The situation of creativity techniques in each criteria.

Table 4. Final ranking of creativity techniques.

\begin{tabular}{ccc}
\hline Rank & Name of Technique & Weight \\
\hline $\mathbf{1}$ & Scenario Building & 0.175 \\
$\mathbf{2}$ & Delphi & 0.163 \\
$\mathbf{3}$ & TKJ & 0.158 \\
$\mathbf{4}$ & Story Boarding & 0.120 \\
$\mathbf{5}$ & Synectics & 0.113 \\
$\mathbf{6}$ & Brainstorming & 0.097 \\
$\mathbf{7}$ & Lateral Thinking & 0.088 \\
$\mathbf{8}$ & Mind Mapping & 0.085 \\
\hline
\end{tabular}

creativity technique for implication in CE projects meetings in uncertainty conditions is Scenario Building. Also Delphi has been identified as the second technique proposed in these conditions.

\section{Conclusions}

Although there are many advantages of team working in PD CE projects, the performance of teams would be limited or even hampered in different conditions such as; projects face with complicated problems or uncertainty. In such situation, project managers need to have creative members for decision making and the scope of the decisions makers would be from different levels of organizational hierarchy. On the other hand, due to several barriers we can't expect to have creative team member in ordinary teams, especially in PD CE projects that team members are from different functional departments of the company. Using creativity and innovation techniques to develop creative idea in teams meetings is one of the important and best solutions to overcome to the limitations of decision making in CE projects. This approach also learns to staff to improve their ability to spread their 
decision space and way of thinking.

To ensure to have a creative team, it is important to understand the effective criteria of successful CE team, particularly when the project faces with sensitive and complicated problems. In this paper as a first step, these criteria have been identified and weighted. Next and based on identified criteria, the related creativity techniques with team work meetings have been ranked.

According to the results, Scenario Building has been identified as a best technique in this condition. Since scenarios are narrative of alternative environments in which todays decisions may be played out, this technique would be a powerful tool to contemplate the range of possible futures [41]. Few managers or experts have the opportunity of thinking about the future. So Scenario building can offer a non-linear and dynamic way of thinking to deal with complexity, and consider to multiple variables of organizational problems simultaneously. There are several topics that are related with this study. Measuring performance of identified creativity techniques in CE projects teams, and consideration of the effects of these techniques in different case studies can be suggested for futures researches.

\section{REFERENCES}

[1] A. Bernard and N. Perry, "Concurrent Cost Engineering for Decisional and Operational Process Enhancement in a Foundry," International Journal of Production Economics, Vol. 109, No. 1-2, 2007, pp. 2-11. doi:10.1016/j.ijpe.2006.11.001

[2] S. Bordoloi and H. H. Guerrero, "Design for Control: A New Perspective on Process and Product Innovation," International Journal of Production Economics, Vol. 113, No. 1, 2008, pp. 346-358. doi:10.1016/j.ijpe.2007.02.043

[3] R. Addo-Tenkorang, "Concurrent Engineering (CE): A Review Literature Report," Proceedings of the World Congress on Engineering and Computer Science, San Francisco, 19-21 October 2011, pp. 1074-1080.

[4] A. N. R. Callaghan, "Survey of Concurrent Engineering Practices and Their Impact of Firm Performance," The Third World Congress of Structural and Multidisciplinary Optimization, Amherst, 17-21 May 1999, pp. 1-6.

[5] M. Krömker, "An Infrastructure to Support Concurrent Engineering in Bid Preparation,” Computers in Industry, Vol. 33, No. 2-3, 1998, pp. 201-208. doi:10.1016/S0166-3615(97)00025-0

[6] B. A. Moges and H. Petri, "Concurrent Engineering Yesterday, Today and Tomorrow, Improving Complex Systems Today,” Springer, Berlin, 2011.

[7] T. Kekale and A. Aslani, "Identification and Ranking of Related Creativity and Innovation Techniques with Creation of Collective Strategy by Using MADM Models Based on Fuzzy Approach,” CIVILICA, Tehran, 2010.

[8] T. Aghaee, "Creativity and Innovation in Humans and
Organizations,” Terme Publisher, Themiscyra, 2008.

[9] J. P. Pennell and R. I. Winner, "Concurrent Engineering: Practices and Prospects," Global Telecommunications Conference and Exhibition Communications Technology for the 1990s and Beyond, Dallas, 27-30 November 1989, pp. 647-655. doi:10.1109/GLOCOM.1989.64049

[10] T. O. Kowang, "New Product Development in Multi-Location R\&D Organization: A Concurrent Engineering Approach,” African Journal of Business Management, Vol. 5, No. 6, 2011, pp. 2264-2275.

[11] G. Loureiro, “A Systems and Concurrent Engineering Framework for the Integrated Development of Space Products,” Acta Astronautica, Vol. 53, No. 12, 2003, pp. 945-961. doi:10.1016/S0094-5765(02)00272-2

[12] S. C. Skalak, "Implementing Concurrent Engineering in Small Companies,” Taylor \& Francis E-Library, London, 2005

[13] N. Stankovic and T. Tillo, "Concurrent Software Engineering Project," Journal of Information Technology Education, Vol. 8, 2009, pp. 27-41.

[14] A. Deshpande, "Improving Concurrent Engineering Practices Team Performance: From the Lenses of Social Cognitive Theory and Expectation-States Theory,” Decision Sciences Institute, Atlanta, 2007.

[15] T. A. Boyle, "Concurrent Engineering Teams II: Performance Consequences of Usage," Team Performance Management, Vol. 12, No. 5-6, 2006, pp. 125-137. doi:10.1108/13527590610687893

[16] D. Malvius, "Integrated Information Management in Complex Product Development,” Ph.D. Thesis, KTH University, Stockholm, 2009.

[17] D. Greenman, “Concurrent Teams, Engineering Capability Development Manager,” University of Southampton, 2011. www.soton.ac.uk

[18] E. Dane, "Rational Versus Intuitive Problem Solving: How Thinking 'off the Beaten Path' Can Stimulate Creativity,” Psychology of Aesthetics, Creativity, and the Arts, Vol. 5, No. 1, 2011, pp. 3-12.

[19] E. Joachimsthaler, "Hidden in Plain Sight: How to Find and Execute Your Company's Next Big Growth Strategy,” Harvard Business School Press, Boston, 2007.

[20] J. M. Higgins, "101 Creative Problem Solving Techniques: The Handbook of New Ideas for Business,” New Management Publishing, Chicago, 2006.

[21] N. Coade, "Be Creative: The Toolkit for Business Success,” International Thomson Business Press, Stamford, 1997.

[22] K. James, “Organizations and Creativity: Trends in Research, Status of Education and Practice, Agenda for the Future, Handbook of Organizational Creativity,” Elsevier, Amsterdam, 2011.

[23] J. W. Wohinz, “Creativity Techniques, Research Project," Supported by Graz University of Technology, 2011. http://portal.tugraz.at/portal/page/portal/Files/I3710/files/ Lehrveranstaltungen/Creativity_Techniques/Creativity\% 20Techniques\%20ws1011.pdf

[24] A. Aslani, "Identification and Ranking of Effective Ele- 
ments in Order to Success in Creation of Strategy," 7th International Management Conference, Tehran, December 2009.

[25] J. A. Reneke, "A Game Theory Formulation of Decision Making under Conditions of Uncertainty and Risk," Nonlinear Analysis: Theory, Methods \& Applications, Vol. 74, No. 16, 2009, pp. e1239-e1246.

[26] A. Griffin and J. R. Hauser, "Patterns of Communication among Marketing, Engineering and Manufacturing-A Comparison between Two New Product Teams," Management Science, Vol. 38, No. 3, 1992, pp. 360-373. doi:10.1287/mnsc.38.3.360

[27] G. D. Putnik, "Virtual Environments for Dynamically Reconfigurable Concurrent/Collaborative Engineering "Virtual' Teams," CIRP Annals-Manufacturing Technology, Vol. 57, No. 1, 2008, pp. 171-174. doi:10.1016/j.cirp.2008.03.022

[28] V. B. Hinsz, "Positive Reactions to Working in Groups in a Study of Group and Individual Goal Decision-Making," Group Dynamics: Theory, Research, and Practice, Vol. 8, No. 4, 2004. doi:10.1037/1089-2699.8.4.253

[29] L. Trygg, "Concurrent Engineering Practices in Selected Swedish Companies: A Movement or an Activity of the Few?” Journal of Product Innovation Management, Vol. 10, No. 5, 1999, pp. 403-415. doi:10.1016/0737-6782(93)90098-B

[30] J. Hall, "Simultaneous Engineering," Overseas Publishers Association, Amsterdam, 1999.

[31] S. A. Friedley, "Building Team Cohesion: Becoming 'We' Instead of 'Me',' 2005. http://www.nationalforensics.org/journal/vol23no1-16.pdf

[32] M. J. Hatch, “Organization Theory: Modern, Symbolic, and Postmodern Perspectives,” Oxford University Press, Oxford, 2006.

[33] H. Mintzberg, "Strategy Safari: A Guided Tour through the Wilds of Strategic Managemen,” Prentice Hall, Englewood Cliffs, 1998.

[34] S. Soliman, "Systems and Creative Thinking, Center for Advancement of Postgraduate Studies and Research in Engineering Sciences,” Giza, 2005.

[35] C. M. Slem, "Self-Management and Leadership in Concurrent Engineering Design Teams, the Annual Convention of the Western Psychological Association, 2011. http://cla.calpoly.edu/ cslem/slem/Research/wpa.html

[36] Z. Sarmad, "The Research Method in Behavioral Science,” Aghah Publication, Tehran, 2009.

[37] A. Ishizaka, "Review of the Main Developments in the Analytic Hierarchy Process," Expert Systems with Applications, Vol. 38, No. 11, 2011, pp. 14336-14345. doi:10.1016/j.eswa.2011.04.143

[38] T. L. Saaty and K. Peniwati, "Group Decision Making: Drawing out and Reconciling Differences,” RWS Publications, Pittsburgh, 2008.

[39] C. L. Hwang and M. J. Lin, "Group Decision Making Under Multiple Criteria: Methods and Applications," Springer-Verlag, Berlin, 1987.

[40] C.L. Hwang and K. Yoon, "Multiple Attribute Decision Making-Methods and Applications,” Springer-Verlag, Berlin, 1981.

[41] P. Durance, "Scenario Building: Uses and Abuses," Technological Forecasting and Social Change, Vol. 77, No. 9, 2010, pp. 1488-1492. doi:10.1016/j.techfore.2010.06.007 